\title{
Mathematical modeling of vaporization process for a polydisperse ensemble of liquid drops
}

\author{
Irina Alexandrova ${ }^{1}$, Dmitri Alexandrov ${ }^{1}$, and Alexander Ivanov ${ }^{1}$ \\ ${ }^{1}$ Ural Federal University named after the first President of Russia B N Yeltsin
}

July 4,2020

\begin{abstract}
In this paper, we study the vaporization process of a polydisperse ensemble of liquid drops on the basis of a nonlinear set of balance and kinetics equations for the particle-radius distribution function and temperature in the gaseous phase. We found an exact parametric solution to this problem using a modified time variable and the Laplace integral transform method. The distribution function of vaporizing drops as well as its moments, the temperature dynamics in gas, and the unvaporized mass of drops are found. The initial particle-radius distribution shifts to smaller particle radii with increasing the vaporization time. As this takes place, the temperature difference between the drops and gas decreases with time. It is shown that the heat of vaporization and initial total number of particles in the system substantially influence the dynamics of a polydisperse ensemble of liquid drops.
\end{abstract}

\section{Hosted file}

evaporation_paper.pdf available at https://authorea.com/users/339752/articles/465905mathematical-modeling-of-vaporization-process-for-a-polydisperse-ensemble-of-liquiddrops 

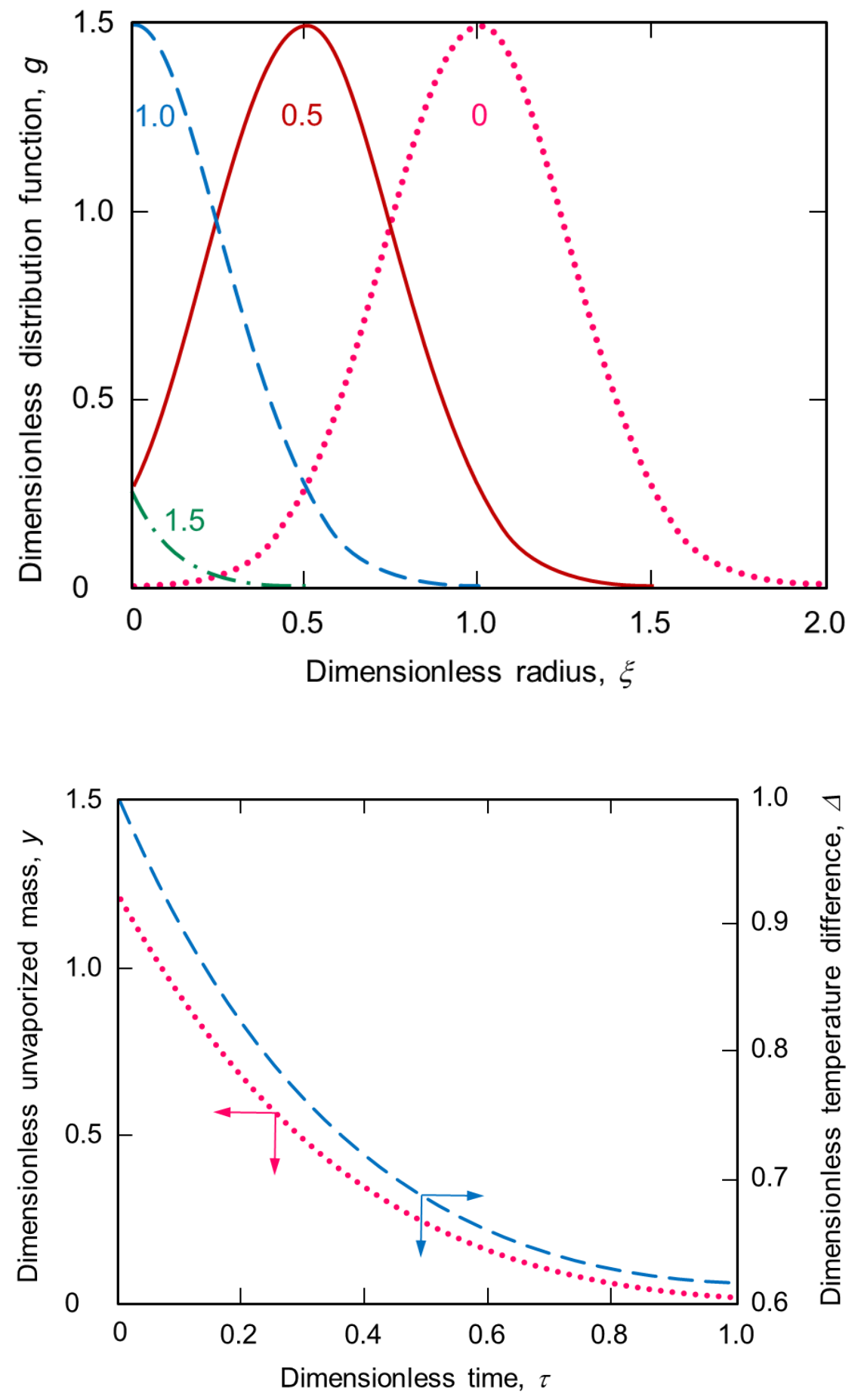

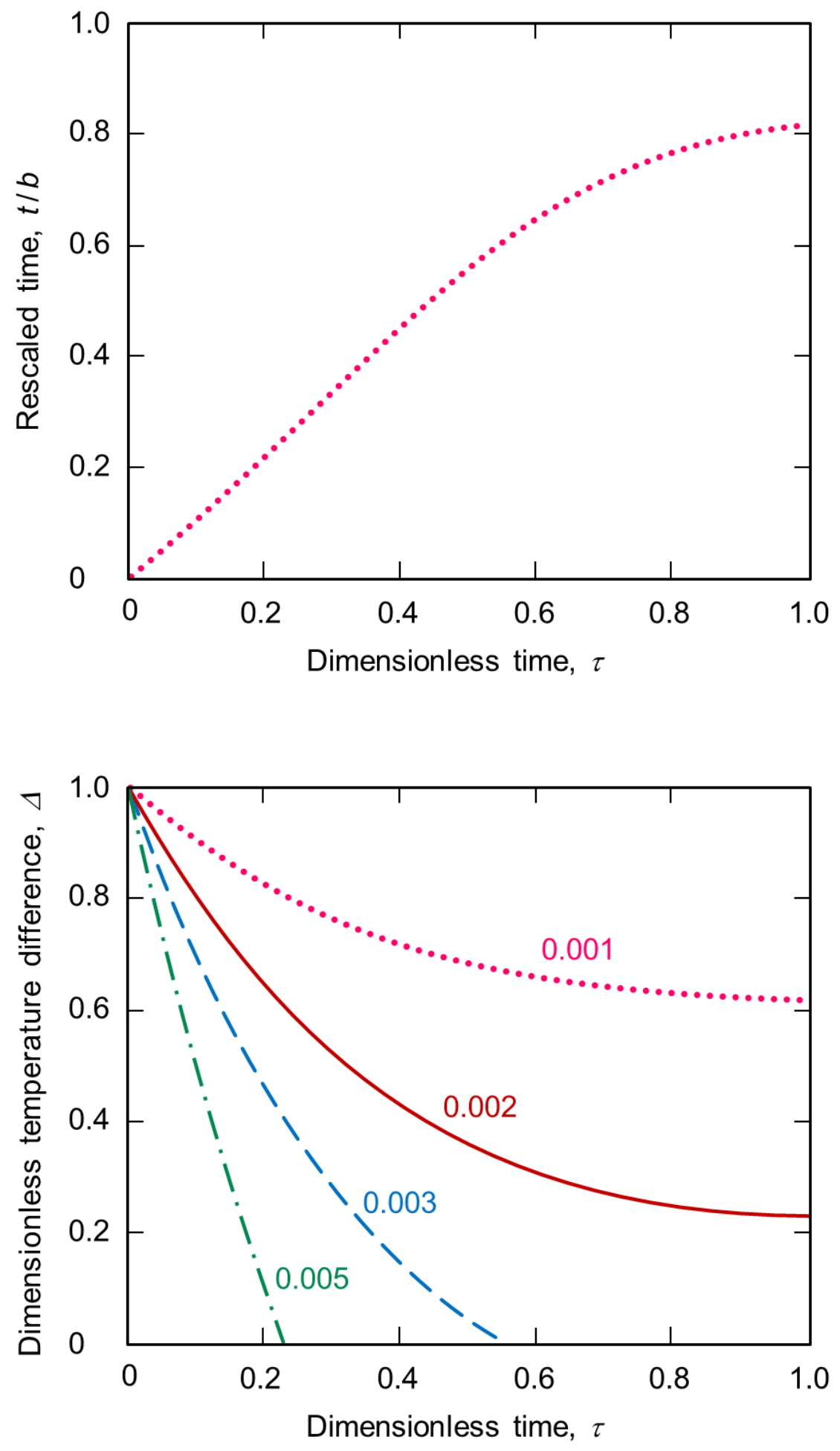


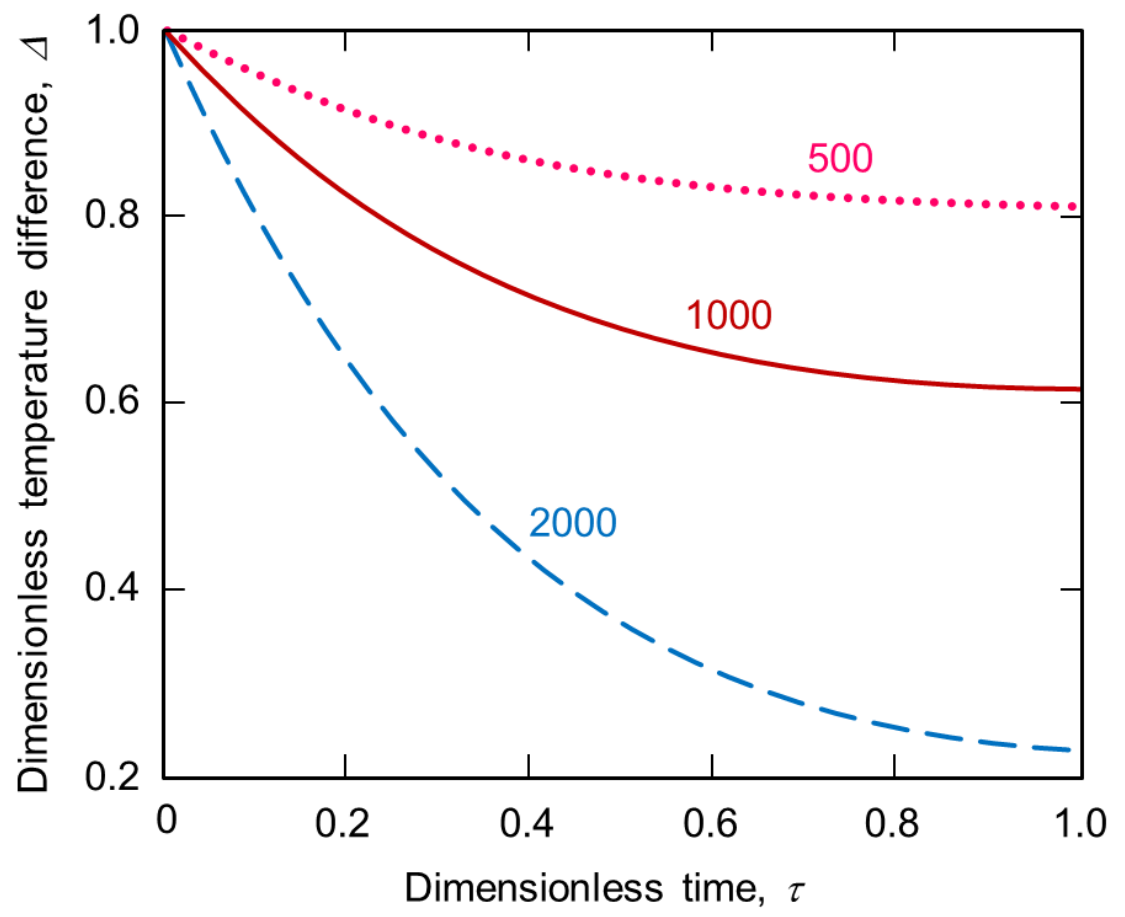

